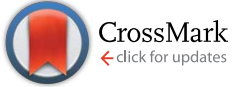

Cite this: Chem. Sci., 2016, 7, 3154

Received 2nd January 2016 Accepted 26th January 2016

DOI: $10.1039 / \mathrm{c} 6 \mathrm{sc} 00011 \mathrm{~h}$

www.rsc.org/chemicalscience

\title{
High yielding synthesis of 2,2'-bipyridine macrocycles, versatile intermediates in the synthesis of rotaxanes $\uparrow$
}

\author{
J. E. M. Lewis, ${ }^{a}$ R. J. Bordoli, ${ }^{b}$ M. Denis, ${ }^{a}$ C. J. Fletcher, ${ }^{a}$ M. Galli, ${ }^{a}$ E. A. Neal, ${ }^{b}$ \\ E. M. Rochette ${ }^{a}$ and S. M. Goldup ${ }^{\star a}$
}

\begin{abstract}
We present an operationally simple approach to 2,2'-bipyridine macrocycles. Our method uses simple starting materials to produce these previously hard to access rotaxane precursors in remarkable yields (typically $>65 \%$ ) across a range of scales $(0.1-5 \mathrm{mmol}$ ). All of the macrocycles reported are efficiently converted $(>90 \%)$ to rotaxanes under AT-CuAAC conditions. With the requisite macrocycles finally available in sufficient quantities, we further demonstrate their long term utility through the first gramscale synthesis of an AT-CuAAC [2]rotaxane and extend this powerful methodology to produce novel Sauvage-type molecular shuttles.
\end{abstract}

\section{Introduction}

The synthesis of mechanically interlocked molecules has progressed significantly since early reports. ${ }^{\mathbf{1 , 2}}$ This was largely made possible by the development of passive template methodologies, inspired by Sauvage and co-workers' seminal work, ${ }^{3}$ in which non-covalent interactions direct mechanical bond formation. ${ }^{4}$ Thus, there exists a range of methodologies for the synthesis of complex interlocked structures in excellent yield in the mechanical bond-forming step.

Despite innovations in the preparation of interlocked molecules, ${ }^{5}$ the synthesis of the requisite functionalised macrocyclic components is often a challenge that can in turn limit the scalability of their synthesis, hindering their investigation for applications such as molecular machines, ${ }^{6}$ materials, ${ }^{7}$ drug delivery agents, ${ }^{8}$ and catalysts. ${ }^{9}$ Indeed the synthesis of macrocyclic molecules more generally remains an important area of investigation due to their unusual properties ${ }^{\mathbf{1 0}}$ combined with the inherent problem of selecting the desired ring closure event over oligomerisation. ${ }^{\mathbf{1 1}}$ A number of strategies have been developed to overcome this including the use of templating interactions to pre-organise the acyclic precursor for ring closure, the preparation of rigid acyclic precursors with restricted rotational degrees of freedom, and expansion of

${ }^{a}$ Chemistry, University of Southampton, Highfield, Southampton, SO17 1BJ, UK. E-mail: s.goldup@soton.ac.uk

${ }^{b}$ School of Biological and Chemical Sciences, Queen Mary University of London, Mile End Road, London, E1 4NS, UK

$\dagger$ Electronic supplementary information (ESI) available: Full synthetic procedures and characterisation of all novel compounds. CCDC 1442682-1442684. For ESI and crystallographic data in CIF or other electronic format see DOI: $10.1039 / \mathrm{c} 6 \mathrm{sc} 00011 \mathrm{~h}$ smaller rings. ${ }^{12}$ Where this is not possible, the most general approach is to carry out the ring-closing step under high dilution, conditions with significant consequences for the scalability of the process. ${ }^{13}$

The contrast in efficiency between the synthesis of the macrocycle and the formation of the mechanical bond is perhaps nowhere more acute than in our small bipyridine macrocycle modification ${ }^{\mathbf{1 4}}$ of Leigh's active template $\mathrm{Cu}$ mediated alkyne-azide cycloaddition ${ }^{15}$ (AT-CuAAC) ${ }^{\mathbf{1 6}}$ reaction. ${ }^{17,18}$ Although AT-CuAAC reactions with small bipyridine macrocycles have been described as "amongst the highest yielding and readily accessible routes to stable interlocked structures", ${ }^{4 c}$ the synthesis of the macrocyclic bipyridine precursor is extremely inefficient, proceeding in just $4-11 \%$ yield. Given the proven utility of the AT-CuAAC reaction for the synthesis of functionalised rotaxanes, ${ }^{\mathbf{1 4 a , 1 9}}$ including examples with multiple mechanical bonds, ${ }^{14 d, 20}$ stabilised organometallic species, ${ }^{\mathbf{1 4 b}}$ stereochemically complex interlocked molecules, ${ }^{14 c}$ interlocked catalysts, ${ }^{9 g}$ and molecular machines, ${ }^{6 \boldsymbol{a}}$ the limitations placed on the application of this powerful methodology by the poor availability of the most efficacious macrocyclic precursors ${ }^{19}$ is a significant barrier to further developments.

Here we report an operationally simple method for the scalable synthesis of bipyridine macrocycles from readily available substrates that effectively removes this limitation. All of the bipyridine macrocycles reported are efficiently converted to [2] rotaxanes under standard conditions. We demonstrate the long term potential of the AT-CuAAC approach with these now readily available substrates through the gram-scale synthesis of a [2]rotaxane catalyst precursor, and a novel synthesis of Sauvage-type molecular shuttles. 
Table 1 Optimisation of the $\mathrm{Ni}$-mediated synthesis of macrocycle $2 \mathrm{a}^{a}$

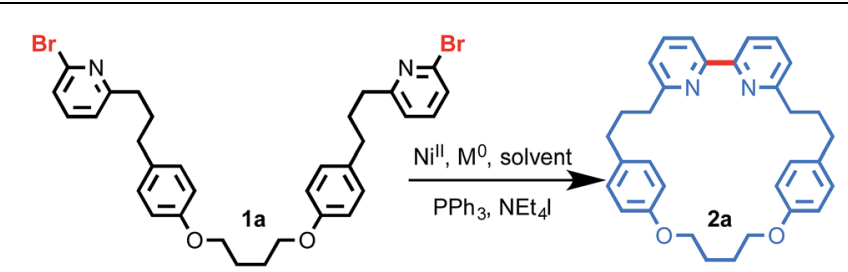

\begin{tabular}{|c|c|c|c|c|}
\hline Entry & $\mathrm{Ni}^{\mathrm{II}}$ source & $\mathbf{M}^{0}$ (equiv.) & & Yield $^{b}$ \\
\hline $1^{c}$ & $\mathrm{NiCl}_{2} \cdot 6 \mathrm{H}_{2} \mathrm{O}$ & $\mathrm{Zn}(2)$ & n.r. & \\
\hline $2^{d}$ & $\mathrm{NiCl}_{2} \cdot 6 \mathrm{H}_{2} \mathrm{O}$ & $\operatorname{Zn}(2)$ & $7 \%$ & \\
\hline $3^{e}$ & $\mathrm{NiCl}_{2} \cdot 6 \mathrm{H}_{2} \mathrm{O}$ & $\mathrm{Zn}(2)$ & $37 \%$ & \\
\hline $4^{e}$ & {$\left[\mathrm{Ni}\left(\mathrm{PPh}_{3}\right)_{2} \mathrm{Br}_{2}\right]$} & $\operatorname{Zn}(2)$ & $60 \%$ & \\
\hline $5^{e, f}$ & {$\left[\mathrm{Ni}\left(\mathrm{PPh}_{3}\right)_{2} \mathrm{Br}_{2}\right]$} & $\operatorname{Zn}(2)$ & $47 \%$ & \\
\hline $6^{e}$ & {$\left[\mathrm{Ni}\left(\mathrm{PPh}_{3}\right)_{2} \mathrm{Br}_{2}\right]$} & $\operatorname{Zn}(4)$ & $50 \%$ & \\
\hline $7^{e}$ & {$\left[\mathrm{Ni}\left(\mathrm{PPh}_{3}\right)_{2} \mathrm{Br}_{2}\right]$} & Mn (2) & $63 \%$ & \\
\hline $8^{e}$ & {$\left[\mathrm{Ni}\left(\mathrm{PPh}_{3}\right)_{2} \mathrm{Br}_{2}\right]$} & Mn (10) & $70 \%$ & \\
\hline
\end{tabular}

${ }^{a}$ Reagents and conditions: $0.1 \mathrm{mmol}$ each $1 \mathrm{a}, \mathrm{Ni}^{\mathrm{II}}, \mathrm{NEt}_{4} \mathrm{I}, 0.4 \mathrm{mmol}$ $\mathrm{PPh}_{3}$ in total, DMF, $50{ }^{\circ} \mathrm{C}, 4 \mathrm{~h} .{ }^{b}$ Determined by ${ }^{1} \mathrm{H}$ NMR analysis of the crude product. ${ }^{c} 5 \mathrm{mM}$ conc. of $1 \mathrm{a} .{ }^{d} 0.05 \mathrm{M}$ conc. of $1 \mathrm{a} .{ }^{e}$ Pseudohigh dilution ( $4 \mathrm{~h}$ addition, $0.05 \mathrm{M}$ final conc. of 1a). ${ }^{f}$ THF as solvent. n.r. $=$ no reaction.

\section{Results and discussion}

\section{A new Ni-mediated macrocyclisation}

Bipyridine macrocycles suitable for AT-CuAAC reactions such as $\mathbf{2 a}$ are typically synthesised via a double Williamson cyclisation of a pre-formed bipyridine precursor. ${ }^{14,16 b, 21}$ However, the preferred trans-rotamer of the bipyridine unit ${ }^{22}$ disfavours the desired cyclisation, leading to low yields, particularly in the case of smaller macrocycles. ${ }^{23}$ To overcome this, we resolved to form the ligand during the macrocyclisation reaction.

Previous routes to bipyridine macrocycles have made use of the Ni-mediated reductive coupling ${ }^{24}$ of 2 -halo pyridines ${ }^{25}$ to produce the bipyridine moiety prior to the macrocyclisation step. ${ }^{\mathbf{1 4}, \mathbf{1 6 b}}$ Although Ni-mediated couplings have not been employed as a macrocyclisation reaction for the preparation of bipyridine macrocycles for incorporation into interlocked architectures, ${ }^{26}$ similar reactions have been successful in the key cyclisation step towards cyclic and bicyclic oligoparaphenylenes, ${ }^{27,28}$ as well as limited examples of bi-phenyl and bibenzyl natural products. ${ }^{29}$ Accordingly, dibromo precursor 1a was synthesised from known intermediates in a succinct manner (see ESI $\dagger$ ) and, under high dilution, subjected to conditions based on those developed by the groups of Tiecco and Iyoda for the Ni-mediated intermolecular homo-coupling of 2-halo-pyridines. ${ }^{25 a, c}$ No reaction was observed (Table 1, entry 1 ).

Repeating the same reaction at higher concentration (entry 2) led to consumption of $\mathbf{1 a}$ to give $\mathbf{2 a}$, albeit in low yield. Combining these observations, slow addition of 1a to the preformed $\mathrm{Ni}^{0}$ species under otherwise identical conditions gave macrocycle $2 \mathbf{a}$ in $37 \%$ yield (entry 3 ). A brief screen of reaction conditions revealed that replacing $\mathrm{NiCl}_{2} \cdot 6 \mathrm{H}_{2} \mathrm{O}$ with $\mathrm{NiBr}_{2}$ $\left(\mathrm{PPh}_{3}\right)_{2}$ resulted in an increased yield of $2 \mathbf{a}$ (entry 4 ), whereas
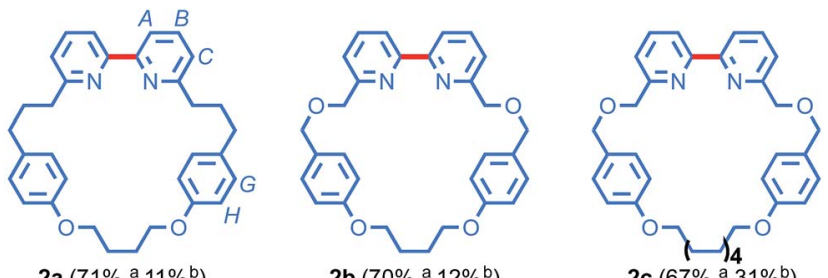

$2 \mathrm{a}\left(71 \%,^{\mathrm{a}} 11 \%{ }^{\mathrm{b}}\right)$
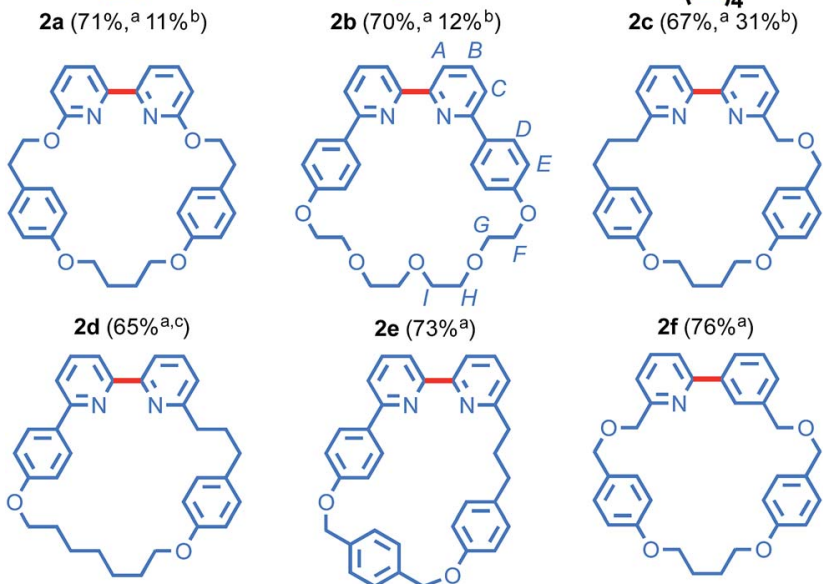

$2 g\left(66 \%,{ }^{a, d} 4 \%\right.$ b)
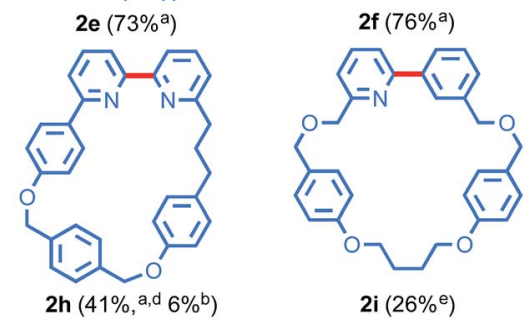

Fig. 1 Synthesis of macrocycles 2 at $2 \mathrm{mmol}$ scale. ${ }^{2}$ Reaction conditions as in Table 1 , entry $8 .{ }^{b}$ Macrocyclisation yield of the best previous

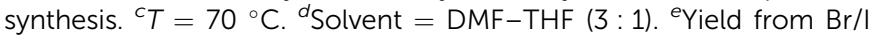
precursor

conducting the reaction in THF, commonly employed in such couplings, ${ }^{25 a}$ led to a less efficient reaction (entry 5). Increasing the equivalents of $\mathrm{Zn}$ reduced the yield of product, with significant proto-dehalogenation observed in the crude mixture (entry 6). On the hypothesis that this was due to halogen-zinc exchange competing with the desired Ni-mediated process, $\mathrm{Mn}$ was substituted for $\mathrm{Zn}$ leading to an improved yield (entry 7). ${ }^{\mathbf{3 0}}$ Finally, increasing the equivalents of Mn (entry 8) to improve the efficiency of reductive steps during the catalytic cycle, ${ }^{24}$ gave $2 \mathrm{a}$ in $70 \%$ yield.

\section{Preparative scale synthesis of bipyridine macrocycles}

Under our optimised conditions, the preparative scale ( $2 \mathrm{mmol}$ ) reaction of $1 \mathrm{a}$ provided macrocycle $2 \mathbf{a}$ in an excellent $71 \%$ isolated yield (Fig. 1) and so we extended our investigation to a selection of previously reported and novel macrocycles. An ether link proximal to the pyridine unit did not affect the outcome; previously disclosed macrocycles $\mathbf{2 b}$ and $2 \mathbf{c}$ were produced in excellent yields, demonstrating that, unlike Williamson ether methods, the Ni-mediated cyclisation is relatively insensitive to ring size. Furthermore, when the dichloro analogue of $\mathbf{1 b}$ was employed, macrocycle $\mathbf{2 b}$ was produced in $56 \%$ yield, indicating that 2-chloro pyridines are also viable substrates. The reaction also tolerates heteroatom substitution on the pyridine ring (2d) although in this case an elevated temperature was required due to the lower reactivity of the more electron-rich substrate. ${ }^{31}$ Similarly, the reaction tolerates 6-arylsubstitution; sterically hindered macrocycle $2 \mathbf{e}$, a smaller analogue of Sauvage's iconic phenanthroline macrocycle, ${ }^{3}$ was produced in excellent $73 \%$ yield. 
We then extended the Ni-mediated coupling to the synthesis of unsymmetrical bipyridine macrocycles, important intermediates in the synthesis of mechanically chiral molecules. ${ }^{\mathbf{1 4 c}}$ Macrocycle $2 \mathbf{f}$, a hybrid of macrocycles $\mathbf{2 a}$ and $\mathbf{2 b}$ in which the two pyridine moieties are differentiated by a proximal ether unit, was produced in excellent $76 \%$ yield. Initial attempts to extend our approach to previously disclosed macrocycle $\mathbf{2 g}$ were hampered by the poor solubility of $\mathbf{1 g}$ in DMF. This was readily overcome by employing a DMF-THF solvent mixture, leading to $2 \mathrm{~g}$ in $66 \%$ yield, an order of magnitude improvement over the previous synthesis (4\%). When the flexible alkyl chain of $2 \mathbf{g}$ was replaced by a $p$-xylyl moiety to give $\mathbf{2 h}$, the yield of the macrocyclisation reaction fell to $41 \%$, presumably due to the increased strain of the smaller, more rigid macrocycle. However, the yield of $\mathbf{2 h}$ remains significantly higher than previous syntheses ( $6 \%$; see ESI $\dagger$ ) and demonstrates that the Nicoupling can be used to generate more challenging structures.

Finally, we extended our approach to an aryl-pyridine crosscoupling. Initial attempts with the corresponding dibromo precursor delivered $2 \mathbf{i}$ in a low $16 \%$ yield. However, replacing the bromo-benzene moiety with an iodo-benzene starting material raised the yield to $24 \%$, suggesting that there is potential to extend our efficient Ni-mediated ring closure to other biaryl macrocyclic motifs in future.

The Ni-mediated synthesis of bipyridine macrocycles is obviously a dramatic improvement over established procedures in terms of simple reaction yield, by as much as an order of magnitude in some cases. Other key benefits of this methodology include: (i) the Ni-mediated coupling appears relatively insensitive to substrate structure (ring size, pyridine substituents) and tolerates simple modifications (temperature, solvent) where required; (ii) the reaction is capable of producing unsymmetrical bipyridine

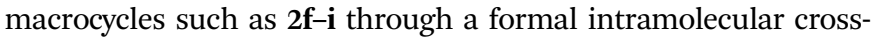
coupling reaction; (iii) bis-halopyridine precursors $\mathbf{1}$ are readily available on scale using simple chemistry and commercially available precursors; (iv) isolation of the product is simplified both by the improved impurity profile of the crude product and by the use of pseudo-high dilution conditions.

This latter point renders the Ni-mediated macrocyclisation highly scalable; whereas previous syntheses of small bipyridine macrocycles $2 \mathbf{a}, \mathbf{2 b}, \mathbf{2} \mathbf{g}$ and $2 \mathbf{h}$ required between 3 and 9 litres of DMF per mmol of product, only $\sim 30 \mathrm{ml}$ of DMF is required to produce each mmol of macrocycle using the method presented here. Using James' EMAC measure of reaction efficiency, ${ }^{\mathbf{1 3}}$ a logarithmic scale taking into account the yield and reaction concentration, this corresponds to an increase in reaction efficiency from EMAC $=3$ to 7 . Furthermore, the excellent reaction yield is maintained across a range of scales; repeating the synthesis of 2a (Scheme 1) with $5 \mathrm{mmol}$ of 1a delivered $1.6 \mathrm{~g}$ of macrocycle $2 \mathrm{a}$ (69\% isolated yield).

\section{Bipyridine macrocycles for the scalable synthesis of [2] rotaxanes in excellent yield}

Macrocycles $\mathbf{2 a - c}$ and $\mathbf{2 g}$ are well precedented in the high yielding AT-CuAAC synthesis of interlocked molecules. ${ }^{\mathbf{9 g}, \mathbf{1 4 , 1 6 b}}$ Pleasingly, preliminary investigations confirmed that

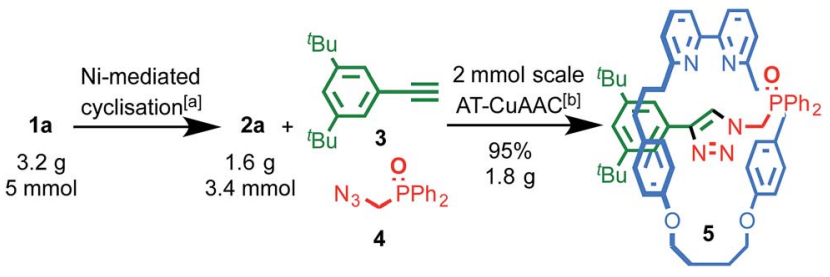

Scheme 1 Large scale macrocyclisation and AT-CuAAC reactions. ${ }^{a}$ Conditions as Table 1 , entry $8 .{ }^{b}\left[\mathrm{Cu}(\mathrm{MeCN})_{4}\right]\left(\mathrm{PF}_{6}\right), \mathrm{N}^{i} \mathrm{Pr}_{2} \mathrm{Et}, \mathrm{CH}_{2} \mathrm{Cl}_{2}-$ $\mathrm{EtOH}(1: 1), 80^{\circ} \mathrm{C}, 18 \mathrm{~h}$.

macrocycles $2 \mathbf{d}-\mathbf{f}$ and $\mathbf{2 h}$ are also excellent rotaxane precursors; under AT-CuAAC conditions with simple alkyne and azide coupling partners, $\mathbf{2 d - f}$ and $\mathbf{2 h}$ are effectively converted ( $>90 \%$ in all cases) to interlocked products (see ESI $\dagger$ ). ${ }^{32}$

Furthermore, with significant quantities of macrocycles 2 in hand we were able for the first time to demonstrate the scalability of the AT-CuAAC reaction. Previous reports have been limited to small scales (typically $0.025 \mathrm{mmol}$ ) by the availability of the macrocycle component. Pleasingly, when the synthesis of interlocked phosphine oxide 5, an advanced precursor of a stimuli-responsive interlocked Au catalyst, ${ }^{9 g}$ was carried out at an 80 -fold larger scale using $0.96 \mathrm{~g}$ of macrocycle $2 \mathrm{a}(2 \mathrm{mmol})$ the isolated yield of the interlocked product was increased relative to our previous report, delivering $1.8 \mathrm{~g}$ (95\%) of 5 in a single synthetic operation.

\section{An efficient AT-CuAAC approach to Sauvage-type molecular shuttles}

Now that bipyridine macrocycles are far more readily available their application in more complex mechanically interlocked molecules and molecular machines is a far more attractive proposition. To capitalise on this, we developed a streamlined synthesis of two Sauvage-type molecular shuttles using macrocycles $2 \mathbf{a}$ and $2 \mathrm{e}$ and compared their behaviour. Such shuttles are usually based on phenanthroline macrocycles and a thread containing a terpyridine and a bipyridine station, assembled using a passive template threading approach. ${ }^{3 c}$ Replacing the phenanthroline macrocycle with its bipyridine analogue and the terpyridine and bipyridine stations with bistriazolylpyridine (btp) and monotriazolylpyridine (mtp) units respectively, ${ }^{33,34}$ greatly facilitates shuttle synthesis using an AT-CuAAC approach. Thus, shuttles 9a and 9e were synthesised in a concise manner from readily available ethynyl pyridine derivatives 6 and 8 through sequential CuAAC couplings of 1,6 bis-azido hexane, delivering $9 \mathrm{a}$ and $9 \mathrm{e}$ in $73 \%$ and $52 \%$ isolated yields respectively in the mechanical bond-forming step (Scheme 2). ${ }^{35}$ The corresponding non-interlocked thread was also synthesised for comparison. With shuttles 9 in hand, we examined their co-conformational behaviour by ${ }^{1} \mathrm{H}$ and ROESY NMR (Fig. 2 and ESI respectively $\dagger$ ).

Analysis of shuttles 9a and 9e by ${ }^{1} \mathrm{H}$ NMR (Fig. 2c and e respectively) suggests that in both cases the macrocycle predominantly occupies the tridentate btp station; significant shifts of thread triazole protons $\mathrm{H}_{p}$ and $\mathrm{H}_{t}$ were observed relative to the non-interlocked thread (Fig. 2d), whereas protons 


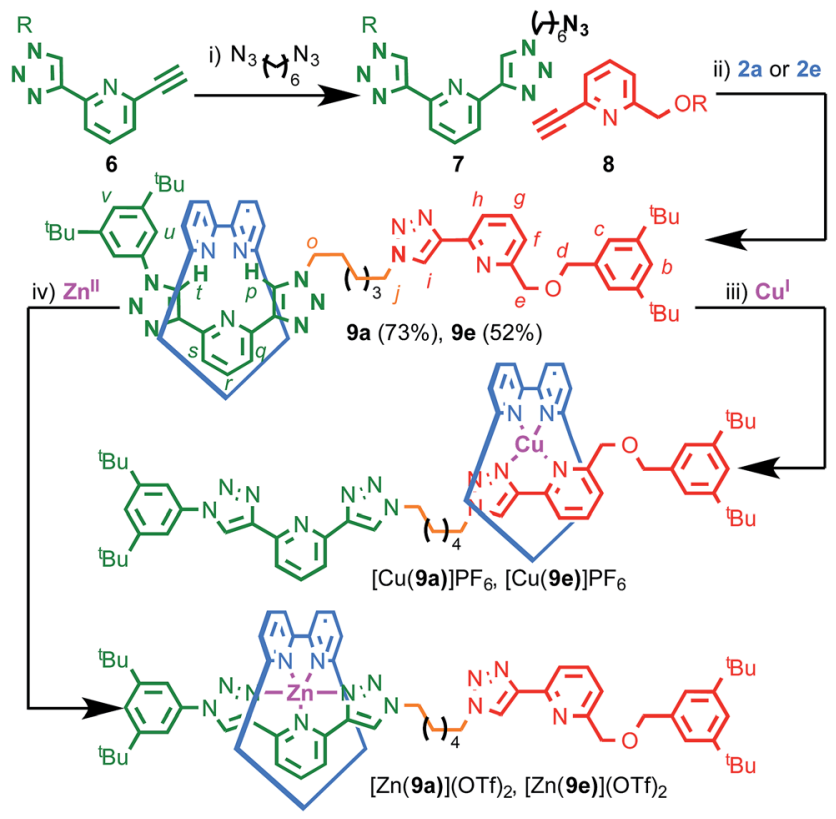

Scheme 2 The AT-CuAAC synthesis and operation of bi-stable molecular shuttles 9. Reagents and conditions: (i) $\left[\mathrm{Cu}\left(\mathrm{MeCN}_{4}\right]\left(\mathrm{PF}_{6}\right)\right.$, $\mathrm{CH}_{2} \mathrm{Cl}_{2}$, rt; (ii) $2 \mathrm{a}$ or $2 \mathrm{e}\left[\mathrm{Cu}(\mathrm{MeCN})_{4}\right]\left(\mathrm{PF}_{6}\right), \mathrm{N}^{\prime} \mathrm{Pr}_{2} \mathrm{Et}, \mathrm{CH}_{2} \mathrm{Cl}_{2}, 80^{\circ} \mathrm{C}$; (iii) $\left[\mathrm{Cu}(\mathrm{MeCN})_{4}\right]\left(\mathrm{PF}_{6}\right), \mathrm{CDCl}_{3}$; (iv) $\mathrm{Zn}(\mathrm{OTf})_{2}, \mathrm{CDCl}_{3} . \mathrm{R}=3,5-\mathrm{di}-{ }^{t} \mathrm{Bu}-\mathrm{C}_{6} \mathrm{H}_{3}$.

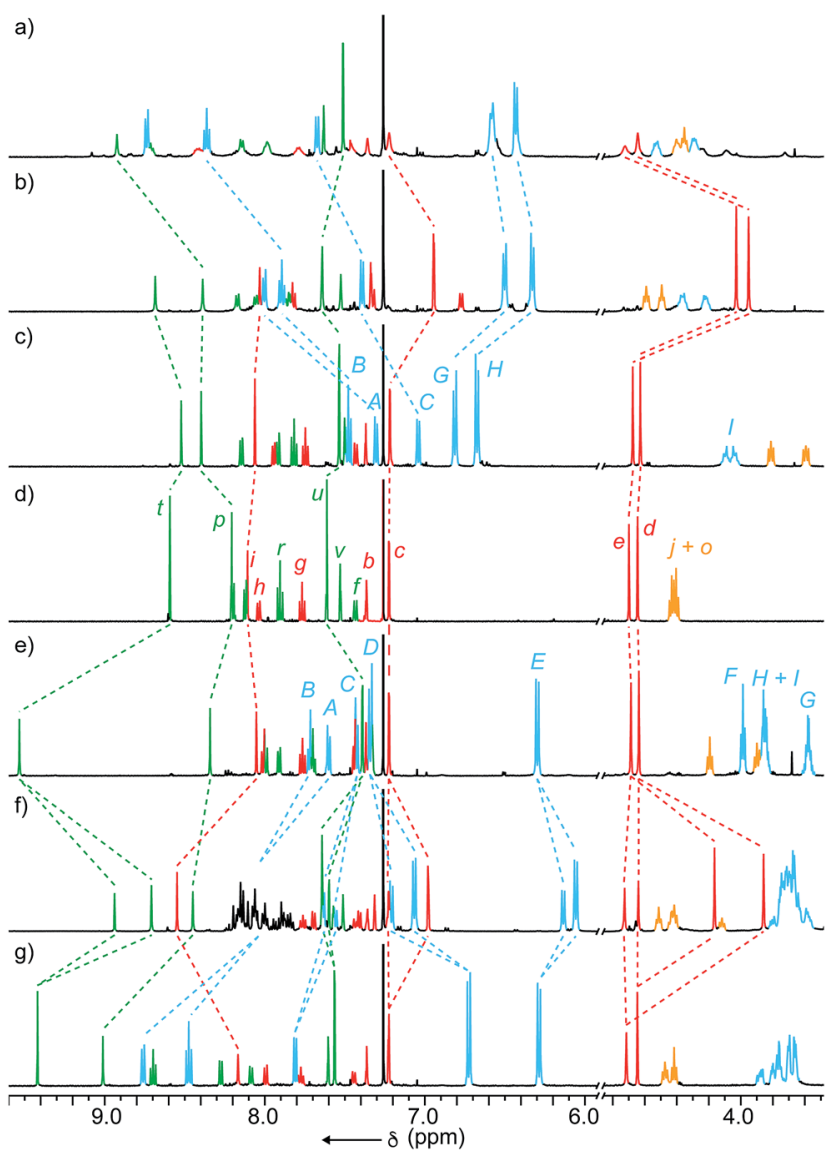

Fig. 2 Partial ${ }^{1} \mathrm{H}$ NMR $\left(500 \mathrm{MHz}, \mathrm{CDCl}_{3}\right)$ of (a) $9 a+\mathrm{Zn}(\mathrm{OTf})_{2}$; (b) $9 a+$ $\left[\mathrm{Cu}(\mathrm{MeCN})_{4}\right]\left(\mathrm{PF}_{6}\right)$; (c) 9a; (d) non-interlocked thread; (e) 9e; (f) 9e + $\left[\mathrm{Cu}(\mathrm{MeCN})_{4}\right]\left(\mathrm{PF}_{6}\right) ;(\mathrm{g}) 9 \mathrm{e}+\mathrm{Zn}(\mathrm{OTf})_{2}$. Selected signals assigned with labels as in Fig. 1 (macrocycle) and Scheme 2 (thread). associate with the bidentate mtp unit remain largely unaffected by the formation of the mechanical bond. ROESY NMR analysis supports this assignment with cross-peaks observed between macrocycle protons and $\mathrm{H}_{q}, \mathrm{H}_{r}$ and $\mathrm{H}_{s}$ of the thread. Given the significant shifts of protons $\mathrm{H}_{p}$ and $\mathrm{H}_{t}$ and our previous observation of $\mathrm{C}-\mathrm{H} \cdots \mathrm{N}$ hydrogen bonding in AT-CuAAC derived rotaxanes, ${ }^{14 a}$ the localisation of the macrocycle over the btp station in rotaxanes 9 is tentatively attributed to the presence of two $\mathrm{C}-\mathrm{H} \cdots \mathrm{N}$ hydrogen-bonding interactions compared with only one in the case of the mtp station.

Next we investigated shuttles 9 in the presence of diamagnetic metal ions $\mathrm{Cu}^{\mathrm{I}}$ and $\mathrm{Zn}^{\mathrm{II}}$ in order to monitor their coconformational behaviour by NMR, as previously reported by Sauvage in the case of phenanthroline derived shuttles. ${ }^{3 c, 36}$ Addition of $\left[\mathrm{Cu}(\mathrm{MeCN})_{4}\right]\left(\mathrm{PF}_{6}\right)$ to $9 a$ led to large changes in the ${ }^{1} \mathrm{H}$ NMR (Fig. 2b) consistent with the expected shuttling of the macrocycle to the bidentate mtp station to form the preferred tetradentate coordination site for $\mathrm{Cu}^{\mathrm{I}}$; protons $\mathrm{H}_{c}, \mathrm{H}_{d}$ and $\mathrm{H}_{e}$ are shielded significantly and ROESY cross-peaks are observed between mtp triazole proton $\mathrm{H}_{i}$ of the thread and alkyl proton $\mathrm{H}_{I}$ of the macrocycle. Replacing $\mathrm{Cu}^{\mathrm{I}}$ with $\mathrm{Zn}^{\mathrm{II}}$ resulted in a new species consistent with the expected complex in which the macrocycle occupies the btp station, providing a pentadentate binding site for $\mathrm{Zn}$; signals associated with the mtp station return to values similar to that of the thread and cross-peaks are observed between the triazole protons $\mathrm{H}_{p}$ and $\mathrm{H}_{t}$ of the btp station and $\mathrm{H}_{I}$ of the macrocycle. Thus it appears that shuttle 9a behaves as a simple bipyridine-mtp/btp analogue of Sauvage's phenanthroline-bipyridine/terpyridine shuttle..$^{3 c}$

The behaviour of shuttle $\mathbf{9 e}$ proved to be more complicated. Surprisingly, addition of $\mathrm{Cu}^{\mathrm{I}}$ led to the formation of two new species in an approximate $2: 1$ ratio (Fig. 2f). Two-dimensional exchange spectroscopy (2D-EXSY) ${ }^{37}$ confirmed that these coconformational isomers are in slow exchange on the NMR timescale with a unimolecular rate constant at room temperature of the order of $10^{-3} \mathrm{~s}^{-1}$ corresponding to an activation barrier of $\sim 21 \mathrm{kcal} \mathrm{mol}^{-1}$. The major co-conformation was assigned as that in which the macrocycle, as initially expected, is localised over the bidentate mtp station, based on the shielding of signals corresponding to $\mathrm{H}_{e}, \mathrm{H}_{d}$ and $\mathrm{H}_{c}$, and ROESY cross-peaks between $\mathrm{H}_{D}$ and $\mathrm{H}_{E}$ of the macrocycle and $\mathrm{H}_{e}$ and $\mathrm{H}_{d}$ of the thread.

Similar analysis confirmed that the minor co-conformation is that in which the macrocycle unexpectedly coordinates the $\mathrm{Cu}^{\mathrm{I}}$ ion at the nominally tridentate btp station, initially suggestive of a five-coordinate $\mathrm{Cu}$ centre. However, Schmittel and co-workers have previously reported the formation of a heteroleptic $\mathrm{Cu}^{\mathrm{I}}$ complex derived from one tridentate and one bidentate ligand in which the metal ion adopts the expected four-coordinate geometry, with the fifth donor not involved in binding to the metal ion. ${ }^{38}$ Although this phenomenon requires further investigation, we tentatively suggest that similar behaviour may account for the minor co-conformation of $[\mathrm{Cu}(\mathbf{9 a})]\left(\mathrm{PF}_{6}\right)$, with subtle differences in the secondary interactions $(\mathrm{C}-\mathrm{H} \cdots \pi, \pi \cdots \pi)$ between macrocycles $2 \mathbf{a}$ or $2 \mathbf{e}$ and the thread accounting for the differences observed. 
Finally, replacing $\mathrm{Cu}^{\mathrm{I}}$ with $\mathrm{Zn}^{\mathrm{II}}$ led to a much simpler outcome; a single new species was observed with ${ }^{1} \mathrm{H}$ and ROESY NMR confirming that, in the case of the $\mathrm{Zn}^{\mathrm{II}}$ complex $[\mathrm{Zn}(\mathbf{9 e})](\mathrm{OTf})_{2}$, the macrocycle was located predominantly on the tridentate btp station, as expected (Fig. 2g).

\section{Conclusions}

In conclusion we have presented an extremely efficient, scalable and general Ni-mediated method for the synthesis of small bipyridine macrocycles for the AT-CuAAC reaction in high yield from readily available precursors under pseudo high dilution conditions. Although this preliminary study has focussed on macrocycles similar to those used previously in the AT-CuAAC reaction, Ni-mediated couplings are typically tolerant to a wide range of functional groups ${ }^{24 b}$ and investigations are currently underway to determine the wider substrate scope. These now readily available macrocycles are proven versatile intermediates for the synthesis of interlocked molecules in excellent yield using both active $\mathbf{1 4}^{\mathbf{1 4} \mathbf{1 6}, \mathbf{1 8 a}-\boldsymbol{e}}$ and passive ${ }^{39}$ template methods. Given the scalability of both the macrocycle synthesis and the mechanical bond forming step demonstrated here, and the clear potential to extend the approach to more complex molecules, the AT-CuAAC reaction mediated by bipyridine macrocycles clearly has a bright future in the synthesis of interlocked architectures for a variety of applications.

\section{Acknowledgements}

We thank Fluorochem for the gift of reagents, the EPSRC National Mass Spectrometry Service for HRMS analysis and the EPSRC (EP/L016621/1), Queen Mary, University of London and the University of Southampton for funding. JEML is a European Commission Marie Skłodowska-Curie Fellow. SMG is a Royal Society Research Fellow. This project has received funding from the European Union's Horizon 2020 research and innovation programme under the Marie Sklodowska-Curie grant agreement No 660731.

\section{Notes and references}

1 (a) E. Wasserman, J. Am. Chem. Soc., 1960, 82, 4433-4434; (b) I. T. Harrison and S. Harrison, J. Am. Chem. Soc., 1967, 89, 5723-5724.

2 (a) G. Schill and A. Lüttringhaus, Angew. Chem., Int. Ed. Engl., 1964, 3, 546-547; (b) G. Schill, W. Beckmann and W. Vetter, Angew. Chem., Int. Ed. Engl., 1973, 12, 665-666.

$3(a) \quad$ C. O. Dietrich-Buchecker, J.-P. Sauvage and J.-P. Kintzinger, Tetrahedron Lett., 1983, 24, 5095-5098; (b) C. O. Dietrich-Buchecker, J.-P. Sauvage and J. Kern, J. Am. Chem. Soc., 1984, 106, 3043-3045; (c) R. Dimer, C. Dietrichbuchecker, M. C. Jime and J.-P. Sauvage, Angew. Chem., Int. Ed. Engl., 2000, 1, 3284-3287; (d) J.-P. Collin, C. DietrichBuchecker, P. Gaviña, M. C. Jimenez-Molero and J.-P. Sauvage, Acc. Chem. Res., 2001, 34, 477-487.

4 For reviews on the synthesis of interlocked molecules see: $(a)$ M. S. Vickers and P. D. Beer, Chem. Soc. Rev., 2007, 36, 211-
225; (b) J. F. Stoddart, Chem. Soc. Rev., 2009, 38, 1802-1820; (c) J. E. Beves, B. A. Blight, C. J. Campbell, D. A. Leigh and R. T. McBurney, Angew. Chem., Int. Ed., 2011, 50, 92609327; (d) N. H. Evans and P. D. Beer, Chem. Soc. Rev., 2014, 43, 4658-4683.

5 For reviews on the applications of mechanically interlocked molecules see: (a) K. Ito, Curr. Opin. Solid State Mater. Sci., 2010, 14, 28-34; (b) X. Ma and H. Tian, Chem. Soc. Rev., 2010, 39, 70-80; (c) R. S. Forgan, J.-P. Sauvage and J. F. Stoddart, Chem. Rev., 2011, 111, 5434-5464; (d) V. N. Vukotic and S. J. Loeb, Chem. Soc. Rev., 2012, 41, 5896-5906; (e) E. A. Neal and S. M. Goldup, Chem. Commun., 2014, 50, 5128-5142; $(f)$ S. F. M. van Dongen, S. Cantekin, J. A. A. W. Elemans, A. E. Rowan and R. J. M. Nolte, Chem. Soc. Rev., 2014, 43, 99-122; (g) S. Erbas-Cakmak, D. A. Leigh, C. T. McTernan and A. L. Nussbaumer, Chem. Rev., 2015, 115, 10081-10206; $(h)$ M. Xue, Y. Yang, X. Chi, X. Yan and F. Huang, Chem. Rev., 2015, 115, 7398-7501.

6 Selected recent examples of interlocked molecular machines: (a) B. Lewandowski, G. De Bo, J. W. Ward, M. Papmeyer, S. Kuschel, M. J. Aldegunde, P. M. E. Gramlich, D. Heckmann, S. M. Goldup, D. M. D'Souza, A. E. Fernandes and D. A. Leigh, Science, 2013, 339, 189-193; (b) S. F. M. van Dongen, J. Clerx, K. Nørgaard, T. G. Bloemberg, J. J. L. M. Cornelissen, M. A. Trakselis, S. W. Nelson, S. J. Benkovic, A. E. Rowan and R. J. M. Nolte, Nat. Chem., 2013, 5, 945-951; (c) G. Ragazzon, M. Baroncini, S. Silvi, M. Venturi and A. Credi, Nat. Nanotechnol., 2014, 10, 70-75; (d) C. Cheng, P. R. McGonigal, S. T. Schneebeli, H. Li, N. A. Vermeulen, C. Ke and J. F. Stoddart, Nat. Nanotechnol., 2015, 10, 547-553. 7 Selected reviews and recent examples of interlocked materials: (a) T. Takata, Polym. J., 2006, 38, 1-20; (b) M. J. Frampton and H. L. Anderson, Angew. Chem., Int. Ed., 2007, 46, 1028-1064; (c) A. Harada, Y. Takashima and H. Yamaguchi, Chem. Soc. Rev., 2009, 38, 875-882; (d) F. L. Thorp-Greenwood, A. N. Kulak and M. J. Hardie, Nat. Chem., 2015, 7, 526-531; (e) M. Franz, J. A. Januszewski, D. Wendinger, C. Neiss, L. D. Movsisyan, F. Hampel, H. L. Anderson, A. Görling and R. R. Tykwinski, Angew. Chem., Int. Ed., 2015, 54, 6645-6649.

8 Selected examples of interlocked drug delivery systems: $(a)$ A. Fernandes, A. Viterisi, F. Coutrot, S. Potok, D. A. Leigh, V. Aucagne and S. Papot, Angew. Chem., 2009, 121, 65656569; (b) M. W. Ambrogio, C. R. Thomas, Y.-L. Zhao, J. I. Zink and J. F. Stoddart, Acc. Chem. Res., 2011, 44, 903913; (c) R. Barat, T. Legigan, I. Tranoy-Opalinski, B. Renoux, E. Péraudeau, J. Clarhaut, P. Poinot, A. E. Fernandes, V. Aucagne, D. A. Leigh and S. Papot, Chem. Sci., 2015, 6, 2608-2613.

9 Selected examples of interlocked catalysts: (a) J. Berná, M. Alajarín and R.-A. Orenes, J. Am. Chem. Soc., 2010, 132, 10741-10747; (b) V. Blanco, A. Carlone, K. D. Hänni, D. A. Leigh and B. Lewandowski, Angew. Chem., Int. Ed., 2012, 51, 5166-5169; (c) C. B. Caputo, K. Zhu, V. N. Vukotic, S. J. Loeb and D. W. Stephan, Angew. Chem., 
Int. Ed., 2013, 52, 960-963; (d) V. Blanco, D. A. Leigh, U. Lewandowska, B. Lewandowski and V. Marcos, J. Am. Chem. Soc., 2014, 136, 15775-15780; (e) V. Blanco, D. A. Leigh, V. Marcos, J. A. Morales-Serna and A. L. Nussbaumer, J. Am. Chem. Soc., 2014, 136, 4905-4908; (f) J. Beswick, V. Blanco, G. De Bo, D. A. Leigh, U. Lewandowska, B. Lewandowski and K. Mishiro, Chem. Sci., 2015, 6, 140; $(g)$ M. Galli, J. E. M. Lewis and S. M. Goldup, Angew. Chem., Int. Ed., 2015, 54, 1354513549.

10 For selected recent examples of macrocycles for medicinal, materials, catalytic and sensing applications see: (a) T. Ema, D. Tanida and T. Sakai, J. Am. Chem. Soc., 2007, 129, 10591; (b) K. Sato, Y. Itoh and T. Aida, J. Am. Chem. Soc., 2011, 133, 13767; (c) S. Dawn, M. B. Dewal, D. Sobransingh, M. C. Paderes, A. C. Wibowo, M. D. Smith, J. A. Krause, P. J. Pellechia and L. S. Shimizu, J. Am. Chem. Soc., 2011, 133, 7032; (d) Z. Liu, M. Frasconi, J. Lei, Z. J. Brown, Z. Zhu, D. Cao, J. Iehl, G. Liu, A. C. Fahrenbach, Y. Y. Botros, O. K. Farha, J. T. Hupp, C. A. Mirkin and J. F. Stoddart, Nat. Commun., 2013, 4, 1855; (e) A. K. Yudin, Chem. Sci., 2015, 6, 30.

11 For a recent review on the synthesis of macrocycles see: V. Martí-Centelles, M. D. Pandey, M. I. Burguete and S. V. Luis, Chem. Rev., 2015, 115, 8736-8834.

12 For selected examples of the high yielding synthesis of macrocycles using various combinations of these strategies see: (a) T. Ogoshi, T. Aoki, K. Kitajima, S. Fujinami, T. Yamagishi and Y. Nakamoto, J. Org. Chem., 2011, 76, 328-331; (b) S. Guieu, A. K. Crane and M. J. MacLachlan, Chem. Commun., 2011, 47, 1169-1171; (c) J. Xia, J. W. Bacon and R. Jasti, Chem. Sci., 2012, 3, 3018-3021; (d) S. Lee, C.-H. Chen and A. H. Flood, Nat. Chem., 2013, 5, 704-710; (e) A.-C. Bédard, S. Régnier and S. K. Collins, Green Chem., 2013, 15, 1962-1966; (f) M. Lisbjerg, B. M. Jessen, B. Rasmussen, B. E. Nielsen, A. Ø. Madsen and M. Pittelkow, Chem. Sci., 2014, 5, 2647-2650; $(g)$ T. Boinski, A. Cieszkowski, B. Rosa and A. Szumna, J. Org. Chem., 2015, 80, 3488-3495; (h) S. Mangold and R. H. Grubbs, Chem. Sci., 2015, 6, 4561-9; ( $i$ ) C. Kitsiou, J. J. Hindes, P. I'Anson, P. Jackson, T. C. Wilson, E. K. Daly, H. R. Felstead, P. Hearnshaw and W. P. Unsworth, Angew. Chem., Int. Ed., 2015, 54, 1579415798.

13 For a recent review that discusses the challenges of high dilution synthesis from a medicinal chemistry perspective, including the development of the EMAC measure of synthetic efficiency, see: J. C. Collins and K. James, Med. Chem. Commun., 2012, 3, 1489-1495.

14 (a) H. Lahlali, K. Jobe, M. Watkinson and S. M. Goldup, Angew. Chem., Int. Ed., 2011, 50, 4151-4155; (b) J. Winn, A. Pinczewska and S. M. Goldup, J. Am. Chem. Soc., 2013, 135, 13318-13321; (c) R. J. Bordoli and S. M. Goldup, J. Am. Chem. Soc., 2014, 136, 4817-4820; (d) E. A. Neal and S. M. Goldup, Chem. Sci., 2015, 6, 2398-2404.

15 (a) C. W. Tornøe, C. Christensen and M. Meldal, J. Org. Chem., 2002, 67, 3057-3064; (b) V. V. Rostovtsev,
L. G. Green, V. V. Fokin and K. B. Sharpless, Angew. Chem., Int. Ed., 2002, 41, 2596-2599.

16 (a) V. Aucagne, K. D. Hänni, D. A. Leigh, P. J. Lusby and D. B. Walker, J. Am. Chem. Soc., 2006, 128, 2186-2187; (b) V. Aucagne, J. Berna, J. D. Crowley, S. M. Goldup, K. D. Hänni, D. A. Leigh, P. J. Lusby, V. E. Ronaldson, A. M. Z. Slawin, A. Viterisi and D. B. Walker, J. Am. Chem. Soc., 2007, 129, 11950-11963.

17 For a review of the AT concept see: J. D. Crowley, S. M. Goldup, A.-L. Lee, D. A. Leigh and R. T. McBurney, Chem. Soc. Rev., 2009, 38, 1530-1541.

18 For selected examples of other AT bond forming reactions and their applications see: (a) J. D. Crowley, K. D. Hänni, A.-L. Lee and D. A. Leigh, J. Am. Chem. Soc., 2007, 129, 12092-12093; (b) J. Berná, J. D. Crowley, S. M. Goldup, K. D. Hänni, A.-L. Lee and D. A. Leigh, Angew. Chem., Int. Ed., 2007, 46, 5709-5757-13; (c) J. Berná, S. M. Goldup, A.-L. Lee, D. A. Leigh, M. D. Symes, G. Teobaldi and F. Zerbetto, Angew. Chem., Int. Ed., 2008, 47, 4392-4396; (d) J. D. Crowley, K. D. Hänni, D. A. Leigh and A. M. Z. Slawin, J. Am. Chem. Soc., 2010, 132, 5309-5314; (e) J. D. Crowley, S. M. Goldup, N. D. Gowans, D. A. Leigh, V. E. Ronaldson and A. M. Z. Slawin, J. Am. Chem. Soc., 2010, 132, 62436248; (f) S. Saito, E. Takahashi and K. Nakazono, Org. Lett., 2006, 8, 5133-5136; $(g)$ N. Weisbach, Z. Baranová, S. Gauthier, J. H. Reibenspies and J. A. Gladysz, Chem. Commun., 2012, 48, 7562-7564; (h) M. J. Langton, J. D. Matichak, A. L. Thompson and H. L. Anderson, Chem. Sci., 2011, 2, 1897-1901; (i) R. Hayashi, K. Wakatsuki, R. Yamasaki, Y. Mutoh, T. Kasama and S. Saito, Chem. Commun., 2014, 50, 204-206; (j) M. Franz, J. A. Januszewski, D. Wendinger, C. Neiss, L. D. Movsisyan, F. Hampel, H. L. Anderson, A. Görling and R. R. Tykwinski, Angew. Chem., Int. Ed., 2015, 54, 66456649; (k) M. J. Langton, Y. Xiong and P. D. Beer, Chem.Eur. J., 2015, 21, 18910-18914.

19 Small pyridine macrocycles are also been applied in the synthesis of functionalised [2] rotaxanes using the ATCuAAC reaction, albeit in lower yield than their bipyridine analogues: (a) A. Noor, S. C. Moratti and J. D. Crowley, Chem. Sci., 2014, 5, 4283-4290; (b) A. Noor, W. K. C. Lo, S. C. Moratti and J. D. Crowley, Chem. Commun., 2014, 50, 7044-7047.

20 S. M. Goldup, D. A. Leigh, P. R. McGonigal, V. E. Ronaldson and A. M. Z. Slawin, J. Am. Chem. Soc., 2010, 132, 315-320.

21 For selected examples of bipyridine macrocycles for other applications see: (a) E. C. Constable, M. S. Khan, J. Lewis, M. C. Liptrot and P. R. Raithby, Inorg. Chim. Acta, 1991, 181, 207-212; (b) R. B. Hopkins, J. S. Albert, D. Van Engen and A. D. Hamilton, Bioorg. Med. Chem., 1996, 4, 11211128; (c) Z. Wang, A. E. Martell, R. J. Motekaitis and J. H. Reibenspies, Inorg. Chim. Acta, 2000, 300-302, 378383; (d) A. Bencini, A. Bianchi, C. Giorgi, V. Fusi, A. Masotti and P. Paoletti, J. Org. Chem., 2000, 65, 76867689; (e) A. Bencini, A. Bianchi, P. Fornasari, C. Giorgi, P. Paoletti and B. Valtancoli, Polyhedron, 2002, 21, 13291335; (f) A. Puglisi, M. Benaglia, R. Annunziata and 
A. Bologna, Tetrahedron Lett., 2003, 44, 2947-2951; $(g)$ P.-L. Ng, C.-S. Lee, H.-L. Kwong and A. S. C. Chan, Inorg. Chem. Commun., 2005, 8, 769-772; (h) C.-S. Lee, P.-F. Teng, W.-L. Wong, H.-L. Kwong and A. S. C. Chan, Tetrahedron, 2005, 61, 7924-7930; (i) I. Nasso, C. Galaup, F. Havas, P. Tisnès, C. Picard, S. Laurent, L. Vander Elst and R. N. Muller, Inorg. Chem., 2005, 44, 8293-8305; (j) G. Bechara, N. Leygue, C. Galaup, B. Mestre and C. Picard, Tetrahedron Lett., 2009, 50, 6522-6525.

22 C. Kaes, A. Katz and M. W. Hosseini, Chem. Rev., 2000, 100, 3553-3590.

23 In a homologous series, yields of $31 \%, 28 \%, 23 \%$ and $12 \%$ were obtained for 32-, 30-, 28- and 26-membered rings respectively. ${ }^{\mathbf{1 4 a}}$

24 The Ni-mediated reductive coupling of aryl halides was first reported by Semmelhack and co-workers (a) M. F. Semmelhack, P. M. Helquist and L. D. Jones, J. Am. Chem. Soc., 1971, 93, 5908-5910 For an excellent recent review of Ni-mediated coupling reactions see $(b)$ B. M. Rosen, K. W. Quasdorf, D. A. Wilson, N. Zhang, A.-M. Resmerita, N. K. Garg and V. Percec, Chem. Rev., 2011, 111, 1346-1416.

25 For selected examples of the Ni-mediated reductive dimerisation of 2-halo-pyridines see: (a) M. Tiecco, L. Testaferri, M. Tingoli, D. Chianelli and M. Montanucci, Synthesis, 1984, 736-738; (b) J.-C. Chambron and J.-P. Sauvage, Tetrahedron, 1987, 43, 895-904; (c) M. Iyoda, H. Otsuka, K. Sato, N. Nisato and M. Oda, Bull. Chem. Soc. Jpn., 1990, 63, 80-87; (d) N. E. Leadbeater and S. M. Resouly, Tetrahedron Lett., 1999, 40, 4243-4246; (e) K. W. R. de Franca, M. Navarro, E. Leonel, M. Durandetti and J.-Y. Nedelec, J. Org. Chem., 2002, 67, 1838-1842; (f) S. Ishikawa, T. Hamada, K. Manabe and S. Kobayashi, Synthesis, 2005, 2176-2182; (g) G. Ricci, R. Ruzziconi and E. Giorgio, J. Org. Chem., 2005, 70, 1011-1018; (h) J. Peng, X. Liu and Y. Kishi, Tetrahedron Lett., 2011, 52, 2172-2175; (i) L. Liao, X. Kong and X. Duan, J. Org. Chem., 2014, 79, 777-782.

26 For medium-ring cyclic bipyridines synthesised under reductive coupling conditions see: (a) C. Botteghi, A. Schionato and O. De Lucchi, Synth. Commun., 1991, 21, 1819-1823; (b) B. Milani, E. Alessio, G. Mestroni, E. Zangrando, L. Randaccio and G. Consiglio, J. Chem. Soc., Dalton Trans., 1996, 1021-1029; (c) J. Durand, E. Zangrando, C. Carfagna and B. Milani, Dalton Trans., 2008, 2171-2182; (d) T. R. Kelly, Y. Lee and R. J. Mears, J. Org. Chem., 1997, 62, 2774-2781.

27 For a recent review of CPP chemistry see: S. E. Lewis, Chem. Soc. Rev., 2015, 44, 2221-2304.

28 For selected examples see: (a) K. Matsui, Y. Segawa, T. Namikawa, K. Kamada and K. Itami, Chem. Sci., 2013, 4, 84-88; (b) K. Matsui, Y. Segawa and K. Itami, J. Am. Chem. Soc., 2014, 136, 16452-16458; (c) E. Kayahara, V. K. Patel and S. Yamago, J. Am. Chem. Soc., 2014, 136, 2284-2287; (d) Y. Ishii, S. Matsuura, Y. Segawa and K. Itami, Org. Lett., 2014, 16, 2174-2176; (e) T. Kuwabara, J. Orii, Y. Segawa and K. Itami, Angew. Chem., Int. Ed., 2015, 54, 9646-9649; (f) Y. Segawa, T. Kuwabara, K. Matsui, S. Kawai and K. Itami, Tetrahedron, 2015, 71, 4500-13.

29 For a recent review see: (a) D. C. Harrowven and S. L. Kostiuk, Nat. Prod. Rep., 2012, 29, 223-242. For selected examples see: ; (b) M. Iyoda, M. Sakaitani, H. Otsuka and M. Oda, Tetrahedron Lett., 1985, 26, 47774780; (c) K. C. Nicolaou, X.-J. Chu, J. M. Ramanjulu, S. Natarajan, S. Brase, F. Rubsam and C. N. C. Boddy, Angew. Chem., Int. Ed. Engl., 1997, 36, 1539-1540; (d) A. Carbonnelle, E. G. Zamora, R. Beugelmans and G. Roussi, Tetrahedron Lett., 1998, 39, 4471-4472; (e) B. H. Lipshutz, P. Müller and D. Leinweber, Tetrahedron Lett., 1999, 40, 3677-3680; (f) A. Berthelot, S. Piguel, G. Le Dour and J. Vidal, J. Org. Chem., 2003, 68, 9835-9838; $(g)$ N. Basse, S. Piguel, D. Papapostolou, A. Ferrier-Berthelot, N. Richy, M. Pagano, P. Sarthou, J. Sobczak-Thépot, M. Reboud-Ravaux and J. Vidal, J. Med. Chem., 2007, 50, 2842-2850.

$30 \mathrm{Mn}$ has previously been shown not to undergo direct halogen metal exchange processes under similar conditions. See: D. A. Everson, R. Shrestha and D. J. Weix, J. Am. Chem. Soc., 2010, 132, 920-921.

31 At $50{ }^{\circ} \mathrm{C}$ a significant quantity of the dimeric product was isolated and characterised. See $\mathrm{ESI}^{\dagger}$

32 In the case of $\mathbf{2 d}$ an excess of half-threads was required. In the case of more rigid, hindered macrocycle $2 \mathbf{h}$ a less sterically hindered benzylic azide was required. See ESI for full details $\dagger$.

33 For recent reviews on triazole-based ligands see: (a) H. Struthers, T. L. Mindt and R. Schibli, Dalton Trans., 2010, 39, 675; (b) J. D. Crowley and D. A. McMorran, Top. Heterocycl. Chem., 2012, 28, 31; (c) B. Schulze and U. S. Schubert, Chem. Soc. Rev., 2014, 43, 2522; (d) J. P. Byrne, J. A. Kitchen and T. Gunnlaugsson, Chem. Soc. Rev., 2014, 43, 5302.

34 For selected examples of pyridyl-triazole coordination complexes see: (a) Y. Li, J. C. Huffman and A. H. Flood, Chem. Commun., 2007, 2692; (b) M. Obata, A. Kitamura, A. Mori, C. Kameyama, J. A. Czaplewska, R. Tanaka, I. Kinoshita, T. Kusumoto, H. Hashimoto, M. Harada, Y. Mikata, T. Funabiki and S. Yano, Dalton Trans., 2008, 3292; (c) D. Schweinfurth, K. I. Hardcastle and U. H. F. Bunz, Chem. Commun., 2008, 2203; (d) D. Schweinfurth, R. Pattacini, S. Strobel and B. Sarkar, Dalton Trans., 2009, 9291; (e) B. Happ, C. Friebe, A. Winter, M. D. Hager, R. Hoogenboom and U. S. Schubert, Chem.-Asian J., 2009, 4, 154; (f) K. J. Kilpin, E. L. Gavey, C. J. McAdam, C. B. Anderson, S. J. Lind, C. C. Keep, K. C. Gordon and J. D. Crowley, Inorg. Chem., 2011, 50, 6334; (g) T. Y. Kim, A. B. S. Elliott, K. J. Shaffer, J. C. McAdam, K. C. Gordon and J. D. Crowley, Polyhedron, 2013, 52, 1391; (h) Y. Li, L. Zhao, A. Y.-Y. Tam, K. M.-C. Wong, L. Wu and V. W.-W. Yam, Chem.-Eur. J., 2013, 19, 14496; (i) J. P. Byrne, J. A. Kitchen, O. Kotova, V. Leigh, A. P. Bell, J. J. Boland, M. Albrecht and T. Gunnlaugsson, Dalton Trans., 2014, 43, 196; (j) J. P. Byrne, J. A. Kitchen, J. E. O'Brien, R. D. Peacock and T. Gunnlaugsson, Inorg. Chem., 2015, 54, 1426; $(k)$ 
N. K. Allampally, C.-G. Daniliuc, C. A. Strassert and L. De Cola, Inorg. Chem., 2015, 54, 1588.

35 Shuttle 9a was isolated in 73\% yield in 95\% purity. An analytical sample for use in shuttling experiments was obtained by subjecting a portion of this material to a second round of column chromatography.

36 The use of $\mathrm{Cu}^{\mathrm{I}}$ and $\mathrm{Zn}^{\mathrm{II}}$ allows the co-conformational behaviour of $9 \mathbf{a}$ and $9 \mathbf{e}$ to be monitored readily and in detail by NMR. However, as Sauvage previously reported, ${ }^{3 c}$ although the $\mathrm{Zn}^{\mathrm{II}}$ ion can be removed readily, more forcing conditions (e.g. $\mathrm{KCN})$ are required in the case of $\mathrm{Cu}^{\mathrm{I}}$. Thus although these systems behave as molecular switches, the reversible switching process itself is somewhat cumbersome. We are currently investigating the in situ electrochemical switching $\left(\mathrm{Cu}^{\mathrm{I}} \rightarrow \mathrm{Cu}^{\mathrm{II}}\right)$ behaviour of such shuttles and these results will be reported in due course.

37 C. L. Perrin and T. J. Dwyer, Chem. Rev., 1990, 90, 935-967. 38 M. Schmittel, V. Kalsani, R. S. K. Kishore, H. Cölfen and J. W. Bats, J. Am. Chem. Soc., 2005, 127, 11544-11545.

39 C. J. Campbell, D. A. Leigh, I. J. Vitorica-Yrezabal and S. L. Woltering, Angew. Chem., Int. Ed., 2014, 53, 1377113774. 